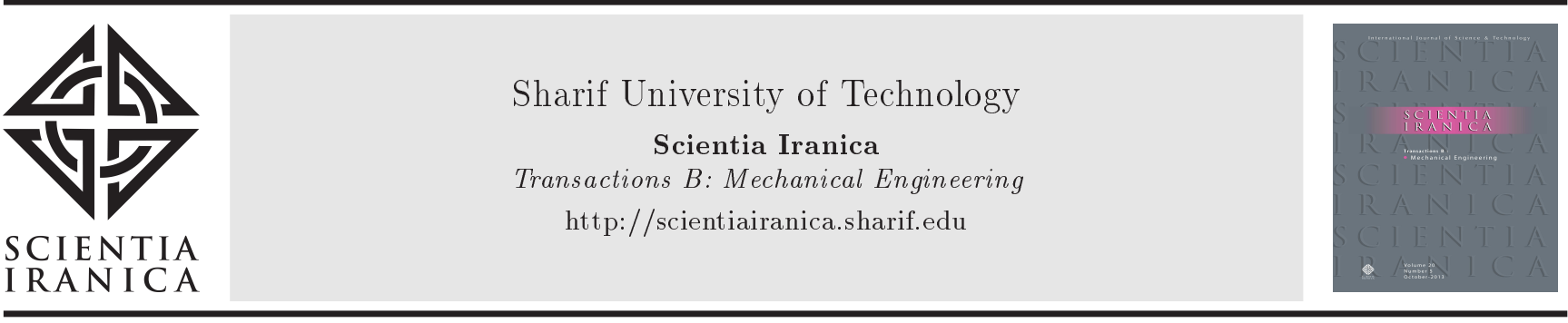

\title{
Vibrational analysis of fullerene hydrides using AIREBO potential
}

\author{
A. Golzari and H. Nejat Pishkenari* \\ Computational Nano Mechanics Laboratory, School of Mechanical Engineering, Sharif University of Technology, Tehran, Iran.
}

Received 25 June 2018; received in revised form 24 December 2018; accepted 26 January 2019

\author{
KEYWORDS \\ Fullerene hydrides; \\ Vibrational analysis; \\ Breathing mode; \\ AIREBO potential; \\ DFT method.
}

\begin{abstract}
In this paper, the vibrational properties of fullerene hydrides with the chemical formula of $\mathrm{C}_{60} \mathrm{H}_{2 n}$ are investigated using a method based on the potential energy of the molecule. The potential used in this methodology is Adaptive Intermolecular Reactive Empirical Bond Order (AIREBO). Using this interatomic potential, some of the most important frequencies of the fullerene hydrides, such as the breathing mode frequency, were calculated and then, analyzed. It was observed that in addition to the number of hydrogen atoms in the structure, their position on the $\mathrm{C}_{60}$ cage had a significant effect on the natural frequency corresponding to a particular mode shape. The results obtained by this method were compared and validated with quantum mechanics and experimental observations. The simulation results demonstrated that the proposed method was capable of calculating the vibrational properties of fullerene hydrides with high precision and low computational cost.
\end{abstract}

(C) 2020 Sharif University of Technology. All rights reserved.

\section{Introduction}

With the discovery of the fullerene molecule in 1985 [1], a great progress occurred in nanoscience. Because of their unique chemical structures, these molecules can be widely used in various fields of science, such as drug delivery [2-6], nanoparticle reinforced composites [7,8], electrical insulating [9], nano-bearing [10,11], nanocar wheels [12-17], supperconductors [18], and nanodiodes [19].

Study of the mechanical and vibrational properties of carbon clusters [20,21] is an important feature affecting their behavior. Given that fullerenes are detected through infrared (IR) spectroscopy of carbon

\footnotetext{
*. Corresponding author.

E-mail addresses: ali.golzari@mech.sharif.ir (A. Golzari); nejat@sharif.edu (H. Nejat Pishkenari)
}

doi: $10.24200 /$ sci. 2019.51307 .2105 steam, an estimation of the natural frequencies of these structures can be very useful in their identification. Also, when $\mathrm{C}_{60}$ reacts with another molecule, its natural frequencies and mode shapes play a very important role. In this regard, some papers have been published on identifying the natural frequencies and the mode shapes of the $\mathrm{C}_{60}$ molecule in various ways, such as Raman and IR spectroscopy [22,23], quantum mechanics [24-26], continuum mechanics [27,28], molecular dynamics simulations [29-31], finite element method [32-35], and so on.

The frequency corresponding to the breathing mode shape as the most important frequency of buckyballs can be easily determined through IR and Raman spectroscopy [36,37]. In this mode shape, all atoms in the molecule experience a simultaneous radial vibration. The great importance of this mode shape is due to its wide applications to the identification of structures and materials [38]. Eisler et al. [36] showed that the frequency of this mode shape could be utilized 
in calculating the size of the molecular cage. Ghavanloo and Fazelzadeh [39] presented an analytical formula to calculate the breathing mode frequency, indicating that this frequency had an inverse relationship with the radius of the molecule. Considering the great significance of this mode shape, in addition to the aforementioned researches, we can find other articles examining the effect of environmental parameters such as temperature and pressure on changes in this frequency in $\mathrm{C}_{60}$ molecule [40-43].

Considering disadvantages of fossil fuels, including air pollution, ozone depletion, global warming, etc., it is necessary to replace them with better alternatives such as hydrogen. Hydrogen is the ideal alternative to fossil fuels because it generates only water steam after burning and it does not lead to any harmful effects. The most important difficulty to use hydrogen gas is its storage and safe transportation due to high reactivity of this gas. One of the best methods for the storage of hydrogen is chemical absorption of this gas in other molecules. Fullerene $\mathrm{C}_{60}$ is proved to be an excellent substrate for absorption of hydrogen by several different methods [44-50]. Synthesis methods of fullerene hydrides have been extensively developing because these hydrides can have potential applications in hydrogen storage. They have also been suggested as one of the IR emission sources in the interstellar space [51]. It is also possible to improve the holetransport property of fullerene molecules by hydrogenation $[52,53]$. The first chemical derivative of fullerene ever synthesized after its discovery was $\mathrm{C}_{60} \mathrm{H}_{36}$ [54], which can be obtained via birch reaction. It contains 4.5 mass $\%$ of hydrogen, making it potentially useful as a hydrogen accumulator [55]. Karpushenkava et al. [56] studied the thermodynamic properties of several isomers of $\mathrm{C}_{60} \mathrm{H}_{36}$ in the ideal gas and crystal states by theoretical methods and checked hydrogen accumulation ability of this molecule. Hydrogen can be inserted into the fullerene cage (endohedral $\mathrm{H} @ \mathrm{C}_{60}$ ) or attached to it from the outside (exohedral $\mathrm{C}_{60} \mathrm{H}_{2 n}$ ). Both hydrogen storage methods by fullerenes have been studied in many articles, but according to research [57], it is desirable for hydrogen to be attached to the fullerene structure from the outside.

In order to access hydrogen energy through its burning, it is necessary to separate it from the fullerene molecule. Several methods have been proposed for the separation of hydrogen. One of these methods is to stimulate the molecule by radiating high-power rays at a specific wavelength to the structure of the molecule. This radiation excites one of the mode shapes related to $\mathrm{C}-\mathrm{H}$ bond of the molecule and, by increasing the intensity of radiation, the amplitude of oscillations increases and eventually, the hydrogen atoms separate from the $\mathrm{C}_{60}$ cage. Surely, the adjustment of the wavelength of the radiated rays requires accurate in- formation about the vibrational properties of $\mathrm{C}_{60} \mathrm{H}_{2 n}$. Having knowledge about the vibrational properties of fullerene hydrides helps to calculate thermodynamic properties of the structure [51]. Also, stimulating specific mode shapes during the chemical reaction, as well as detecting the type of fullerene hydrides using IR and Raman spectroscopy, makes it ever more important to know the values of natural frequencies and the shape modes of these molecules.

Some previous studies have examined the natural frequencies of fullerene hydrides. Bini et al. [58] prepared several samples of $\mathrm{C}_{60} \mathrm{H}_{36}$ by the transfer hydrogenation method and studied the vibrational properties of those molecules by IR and Raman spectroscopy. IR and Raman spectra of hydro fullerenes $\mathrm{C}_{60} \mathrm{H}_{18}, \mathrm{C}_{60} \mathrm{H}_{36}$, and $\mathrm{C}_{60} \mathrm{D}_{18}$ were thoroughly studied using both experimental and computational techniques by Popov et al. [59]. Other works about IR and Raman spectra of $\mathrm{C}_{60} \mathrm{H}_{18}$ and $\mathrm{C}_{60} \mathrm{H}_{36}$ can be found in [60,61]. Generally, interpretation of vibrational spectra of $\mathrm{C}_{60} \mathrm{H}_{2 n}$ is difficult because of uncertainty in the isomeric composition of the samples, presence of impurities, and low intensity of many absorption bonds [51]. Also, one cannot obtain all the natural frequencies of a structure by Raman and IR spectroscopy, while it is the only practical way to identify specific frequencies. It seems that another method should be used for obtaining the vibrational properties of a specific molecule. The first solution to this problem is quantum mechanics technique. A Density Functional Theory (DFT) technique is based on quantum mechanics. Although DFT is a very accurate method for calculating natural frequencies and shape modes of a molecule, it is most often used for molecules with a low number of atoms. Despite high accuracy of DFT, this technique suffers from high computational cost. Therefore, the need for a more efficient methodology seems necessary.

Despite the great importance of determining vibrational properties of fullerene hydrides, this issue is not addressed through a satisfactory method until now. In addition, most of the work has been focused on the two structures of $\mathrm{C}_{60} \mathrm{H}_{18}$ and $\mathrm{C}_{60} \mathrm{H}_{36}$ and other fullerene hydrides with different numbers of hydrogen atoms have not been examined. Moreover, although the breathing mode frequency has been investigated for various carbon clusters, such as fullerenes or nanotubes, study of this frequency for $\mathrm{C}_{60} \mathrm{H}_{2 n}$ structures has not been accomplished in any of the previous works. Therefore, the main scope of this research is to study vibrational properties of fullerene hydrides using a potential energy based method. To calculate the natural frequencies and normal modes of fullerene hydrides, the stiffness matrix of the molecule is computed based on the interatomic potential energy function. The potential function used to model interactions among atoms in fullerene hydrides molecules is Adaptive Intermolecular 
Reactive Empirical Bond Order (AIREBO), which has a high accuracy in predicting natural frequencies of hydrocarbons [31]. Using this method, the vibrational properties of the $\mathrm{C}_{60} \mathrm{H}_{2 n}$ molecules are obtained with $n$ being an integer number ranging from 0 to 18 . To this aim, the frequency related to the breathing mode shape of all of the fullerene hydrides, along with some of their other important frequencies, is calculated. Due to the fact that the breathing mode frequency depends on the radius of the molecule, which has previously been reported by Ghavanloo and Fazelzadeh [39], the radius of gyration of each $\mathrm{C}_{60} \mathrm{H}_{2 n}$ is obtained and its variations in terms of the number of hydrogen atoms are analyzed. As a benchmark for evaluating the accuracy of the proposed potential-based method, the same results have also been obtained through DFT calculations for a special case. The good consistency between the results of the two methods demonstrates the validity of our proposed method. Given that the results of the DFT method are confirmed by laboratory results, it will be observed that there is also a good agreement between the potential based approach and the experimental results. Good precision and high computational speed make this method an effective technique for calculating the vibrational properties of fullerene hydrides or other molecules compared to the quantum mechanics and experimental methods explained in this section.

\section{Fullerene hydrides}

As explained in the introduction section, fullerene hydrides $\mathrm{C}_{60} \mathrm{H}_{2 n}$ are obtained from the chemical reaction of hydrogen with the $\mathrm{C}_{60}$ molecule. The number of possible isomers of $\mathrm{C}_{60} \mathrm{H}_{2 n}$ varies over a wide range from 23 for $\mathrm{C}_{60} \mathrm{H}_{2}$ to about $10^{23}$ for $\mathrm{C}_{60} \mathrm{H}_{2 n}$ [62]. In this study, 39 fullerene hydride molecules with the $\mathrm{C}_{60}$ molecule, $\mathrm{C}_{60} \mathrm{H}_{2 n}$ ( $n$ is an integer number between 1 and 18), are investigated to achieve vibrational properties. In Table 1, the chemical formula of each of the compounds, along with the number of isomers and the symmetry of isomers, is presented. For getting information on the position of hydrogen atoms on the $\mathrm{C}_{60}$ molecule for each of the isomers, study of references $[51,63,64]$ is helpful.

\section{Methodology}

\subsection{AIREBO potential}

The second version of Reactive Empirical Bond Order (REBO) potential is able to properly predict vibrational and elastic properties as well as the energy of small hydrocarbons. However, this potential is not suitable for studying systems with large intermolecular interactions, since this version does not take into account dispersive and non-bonded repulsive effects.

Given these drawbacks, the AIREBO potential,

Table 1. The chemical formula, number of hydrogen atoms, number of isomers, and symmetry of isomers of each molecule.

\begin{tabular}{|c|c|c|c|}
\hline $\begin{array}{l}\text { Compound } \\
\text { name }\end{array}$ & $\begin{array}{c}\text { Number of } \\
\text { hydrogen atoms }\end{array}$ & $\begin{array}{c}\text { Number of } \\
\text { isomers }\end{array}$ & $\begin{array}{l}\text { Symmetry of } \\
\text { isomers }\end{array}$ \\
\hline $\mathrm{C}_{60} \mathrm{H}_{2}$ & 2 & 3 & $C_{2 v}, C_{s}, C_{1}$ \\
\hline $\mathrm{C}_{60} \mathrm{H}_{4}$ & 4 & 4 & $C_{s}($ No. 1$), C_{s}($ No. 2$), C_{s}$ (No. 3$), D_{2 h}$ \\
\hline $\mathrm{C}_{60} \mathrm{H}_{6}$ & 6 & 2 & $D_{3}, C_{3}$ \\
\hline $\mathrm{C}_{60} \mathrm{H}_{8}$ & 8 & 1 & $C_{s}$ \\
\hline $\mathrm{C}_{60} \mathrm{H}_{10}$ & 10 & 1 & $C_{s}$ \\
\hline $\mathrm{C}_{60} \mathrm{H}_{12}$ & 12 & 1 & $C_{1}$ \\
\hline $\mathrm{C}_{60} \mathrm{H}_{14}$ & 14 & 1 & $C_{s}$ \\
\hline $\mathrm{C}_{60} \mathrm{H}_{16}$ & 16 & 1 & $C_{s}$ \\
\hline $\mathrm{C}_{60} \mathrm{H}_{18}$ & 18 & 5 & $C_{3 v}$ (1-2 addition), $C_{3 v}$ (1-4 addition), $C_{2}, C_{3}, C_{3 v}$ \\
\hline $\mathrm{C}_{60} \mathrm{H}_{20}$ & 20 & 2 & $D_{5 d}, C_{s}$ \\
\hline $\mathrm{C}_{60} \mathrm{H}_{22}$ & 22 & 1 & $C_{s}$ \\
\hline $\mathrm{C}_{60} \mathrm{H}_{24}$ & 24 & 2 & $C_{1}, C_{2}$ \\
\hline $\mathrm{C}_{60} \mathrm{H}_{26}$ & 26 & 1 & $C_{s}$ \\
\hline $\mathrm{C}_{60} \mathrm{H}_{28}$ & 28 & 1 & $C_{1}$ \\
\hline $\mathrm{C}_{60} \mathrm{H}_{30}$ & 30 & 1 & $C_{1}$ \\
\hline $\mathrm{C}_{60} \mathrm{H}_{32}$ & 32 & 1 & $C_{1}$ \\
\hline $\mathrm{C}_{60} \mathrm{H}_{34}$ & 34 & 1 & $C_{s}$ \\
\hline $\mathrm{C}_{60} \mathrm{H}_{36}$ & 36 & 10 & $\begin{array}{l}T, C_{1}, T_{h}, D_{3 d}, D_{3 d^{\prime}}, C_{3}(\text { No. } 3) \\
\left.C_{3}(\text { No. } 4), C_{3}(\text { No. } 64), S_{6}(\text { No. } 88), S_{6} \text { (No. } 91\right)\end{array}$ \\
\hline
\end{tabular}


introduced for the first time in 1990 [65], adds two terms to REBO potential. This potential, revised in 2002 [66], can model intermolecular bonds in some carbon allotropes and small hydro-carbons.

The total potential energy of AIREBO potential can be written as:

$$
\begin{aligned}
E_{A I R E B O}= & \frac{1}{2} \sum_{i} \sum_{j \neq i} \\
& {\left[E_{i j}^{R E B O}+E_{i j}^{L J}+\sum_{k \neq i} \sum_{l \neq i, j, k} E_{k i j l}^{\text {Torsion }}\right] . }
\end{aligned}
$$

The first term on the left side is the REBO potential, which consists of two terms for repulsive $\left(V^{R}\right)$ and attractive $\left(V^{A}\right)$ interactions due to valence electrons, and is given by:

$$
E_{R E B O}=\sum_{i} \sum_{j(\succ i)}\left[V^{R}\left(r_{i j}\right)-b_{i j} V^{A}\left(r_{i j}\right)\right],
$$

where $b_{i j}$ is the bond-order potential and $r_{i j}$ is the distance between the nearest pair of atoms. For further illustration see [66]. The component $E_{i j}^{L J}$ is written as:

$$
\begin{aligned}
E_{i j}^{L J}= & S\left(t_{r}\left(r_{i j}\right)\right) S\left(t_{b} b_{i j}^{*}\right) C_{i j} V_{i j}^{L J}\left(r_{i j}\right) \\
& +\left[1-S\left(t_{r}\left(r_{i j}\right)\right)\right] C_{i j} V_{i j}^{L J}\left(r_{i j}\right),
\end{aligned}
$$

where $S(t)$ is a switching function,

$$
S(t)=\theta(-t)+\theta(t) \theta(1-t)\left[1-t^{2}(3-2 t)\right] .
$$

In the above equations, $\theta(t)$ is the Heaviside function and $r_{i j}$ is the distance between pairs of atoms. $t_{r}$ in Eq. (3) is added to control the gradual exclusion of the term $L J$ with respect to $r$. The switch $t_{b}$ indicates the degree of significance of the $L J$ interaction at intermolecular distances. The last switching term $C$ controls the number of intermediate atoms between atoms $i$ and $j$. Finally, the last term $E^{\text {Torsion }}$ is the torsional potential among atoms $i, j, k$, and $l$. This function is written as:

$$
E_{k i j l}^{\text {Torsional }}=\omega_{i k}\left(r_{i k}\right) \omega_{i j}\left(r_{i j}\right) \omega_{j l}\left(r_{j l}\right) V_{\text {Torsion }}\left(\omega_{k i j l}\right),
$$

where:

$$
V_{\text {Torsion }}\left(\omega_{k i j l}\right)=\frac{256}{405} \varepsilon_{k i j l} \cos ^{10}\left(\frac{\omega_{k i j l}}{2}\right)-\frac{\varepsilon_{k i j l}}{2} .
$$

Further elaboration on the terms in the above equations can be found in [67].

\subsection{Calculation of frequencies}

To calculate the natural frequencies and normal modes of fullerene hydrides, we first obtain the energy function of each molecule and then, use the second Newton's equation of motion for each atom as follows:

$$
m_{i} \ddot{\xi}_{i}=-\frac{\partial V}{\partial \xi_{i}}
$$

where $V$ is the energy function based on AIREBO potential; $\xi_{1}, \xi_{2}, \cdots, \xi_{3 N}$ are the displacements in Cartesian coordinates, $\Delta x_{1}, \Delta y_{1}, \Delta z_{1}, \cdots, \Delta z_{N} ; m_{i}$ is the mass of $i$ th atom; and $N$ is the total number of atoms in the molecule. From linear expansion of the right side of Eq. (7), we have:

$$
\begin{aligned}
& \frac{\partial V}{\partial \xi_{i}}= \\
& \left.\quad \frac{\partial V}{\partial \xi_{i}}\right|_{\text {equilibrium }}+\left.\left(\frac{\partial^{2} V}{\partial \xi_{i} \partial \xi_{j}}\right)^{T}\right|_{\text {equilibrium }}\left[\begin{array}{c}
\xi_{1} \\
\xi_{2} \\
\vdots \\
\xi_{3 N}
\end{array}\right] .
\end{aligned}
$$

The first term in the above equation is zero, because there is not any force on each atom in the equilibrium state. We can express the equations of motion for all atoms in the matrix form as follows:

$$
[M](\ddot{\xi})=-[H](\xi)
$$

where $M$ is the mass matrix. This matrix has a diagonal form in which all nonzero elements equal the mass of carbon or hydrogen. $H$ is the Hessian matrix, which is given by:

$$
H_{i j}=\left[\frac{\partial^{2} V}{\partial \xi_{i} \partial \xi_{j}}\right] \text {. }
$$

To calculate the elements of Hessian matrix, we first obtain the potential function of each structure in the minimized state using the conjugate gradient and steepest descent methods. Then, we displace each atom in the positive and negative directions of Cartesian coordinates with a very small value $\delta$ and evaluate the potential function in each position. Finally, $H_{i j}$ can be obtained numerically from the following equation:

$$
H_{i j}=\frac{V_{i+\delta, j+\delta}+V_{i-\delta, j-\delta}-V_{i+\delta, j-\delta}-V_{i-\delta, j+\delta}}{4 \delta^{2}},
$$

where:

$$
\begin{aligned}
& V_{i \pm \delta, j}=V\left(\xi_{1}, \xi_{2}, \ldots, \xi_{i-1}, \xi_{i \pm \delta}, \xi_{i+1}, \ldots, \xi_{3 N}\right), \\
& V_{i, j \pm \delta}=V\left(\xi_{1}, \xi_{2}, \ldots, \xi_{j-1}, \xi_{j \pm \delta}, \xi_{j+1}, \ldots, \xi_{3 N}\right),
\end{aligned}
$$

and $\delta$ is chosen to be $10^{-4} \AA$. By considering a harmonic motion $\xi_{i}=\Lambda_{i} e^{i \omega t}$ in Eq. (9), we will have:

$$
\left([H]-\omega^{2}[M]\right)(\xi) .
$$

According to the above equation, the problem would be reduced to finding the eigenvalues and eigenvectors of the matrix $[M]^{-1}[H]$. 


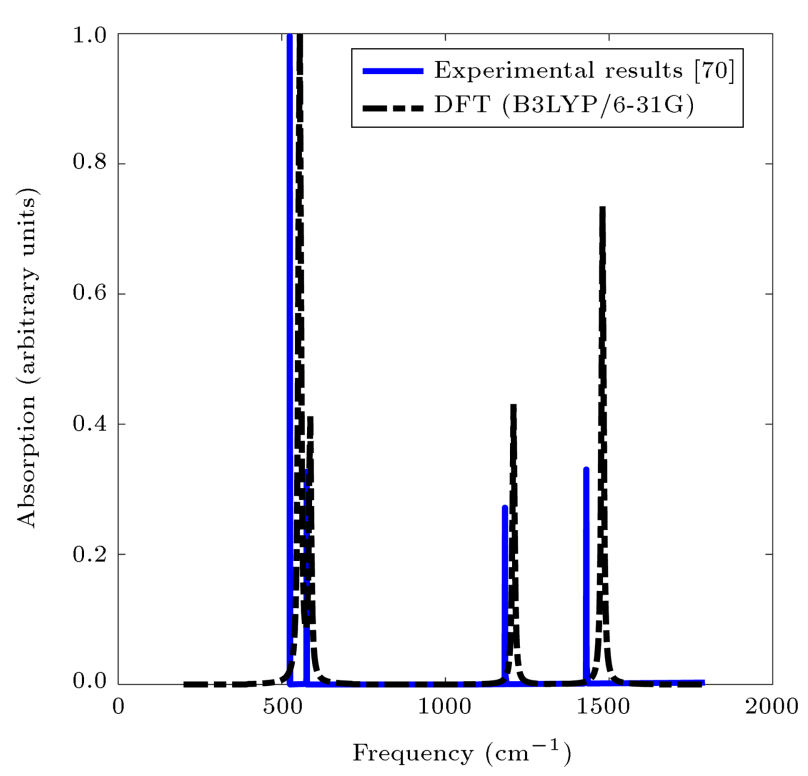

Figure 1. Infrared spectroscopy of the fullerene molecule obtained through both experimental and theoretical (DFT) methods.

Among all the $3 N$ eigenvalues and eigenvectors, six are close to zero. These values account for rigidbody translational and rotational motions of $\mathrm{C}_{60} \mathrm{H}_{2 n}$ molecules. Therefore, after ignoring these rigid-body modes, we reach a set of $3 N-6$ eigenvalues and their corresponding eigenvectors. This process is repeated until all natural frequencies and normal modes of all $\mathrm{C}_{60} \mathrm{H}_{2 n}$ compounds considered in this article are obtained.

\subsection{Quantum mechanics}

A quantum mechanics analysis was performed using DFT (B3LYP [31,68]) on fullerene hydrides. The calculations were performed by setting the basis set as 6-31G $[31,69]$. The results of this method are used as a reference for validating the results of the potentialbased analysis.

In order to demonstrate an agreement between the quantum mechanics and experimental results, IR spectra of the $\mathrm{C}_{60}$ molecule calculated by the DFT method (B3LYP/6-31G) are compared with experimental results reported by Chase et al. [70] (see Figure 1). This comparison shows an appropriate conformity between the results of the two approaches.

\section{Results and discussion}

After minimizing the total potential energy based on AIREBO potential by conjugate gradient and steepest descent methods, the natural frequencies and normal modes of fullerene hydrides $\mathrm{C}_{60} \mathrm{H}_{36}$ are obtained by the methodology explained in Section 3.2. Figure 2 shows the shapes of two fullerene hydride molecules with different hydrogen atoms.
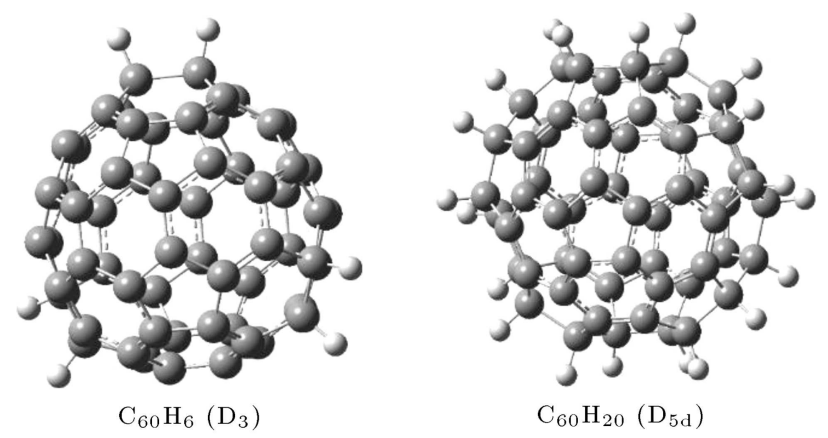

Figure 2. The shapes of two fullerene hydrides having different numbers of atoms.

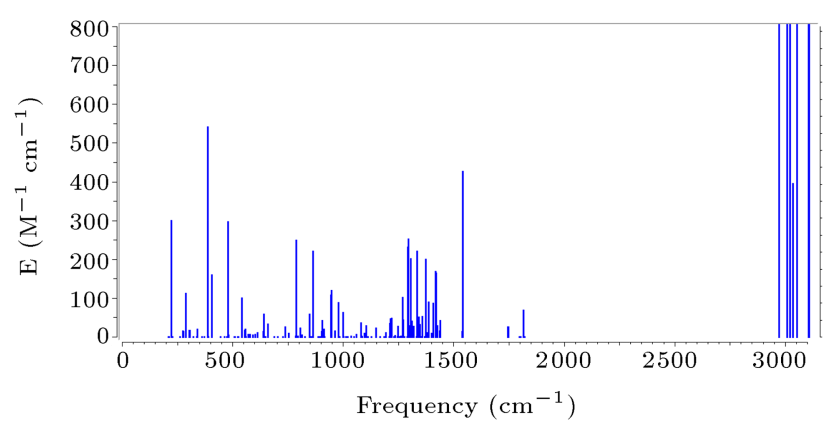

Figure 3. Infrared spectroscopy of $\mathrm{C}_{60} \mathrm{H}_{36}\left(\mathrm{~S}_{6}(\mathrm{No.} 88)\right)$ obtained by Density Functional Theory (DFT) calculations.

Based on [51], the natural frequencies of each hydro fullerene can be divided in two groups: cage vibrations and $\mathrm{C}-\mathrm{H}$ bond vibrations. In the mode shape of a frequency related to cage vibrations, all carbon and hydrogen atoms can move. The range of these frequencies is less than $1900 \mathrm{~cm}^{-1}$. In the mode shape of $\mathrm{C}-\mathrm{H}$ bond vibrations, only the hydrogen and carbon atoms are connected to the $\mathrm{C}-\mathrm{H}$ bonds and can move. In the shape modes associated with this group of frequencies, the movement direction of the carbon and hydrogen atoms connected to a $\mathrm{C}-\mathrm{H}$ bond is along the same $\mathrm{C}-\mathrm{H}$ bond. All frequencies associated with this bond are in the range of $2900 \mathrm{~cm}^{-1}$ to $3100 \mathrm{~cm}^{-1}$. To understand the variations of the frequency spectra of hydro fullerenes, the IR spectrum of one of the $\mathrm{C}_{60} \mathrm{H}_{36}$ isomers is shown in Figure 3.

One of the most important frequencies of fullerene families, which can easily be identified through Raman and IR spectroscopy, is the breathing mode frequency $\left(\mathrm{A}_{g}(1)\right)$ in which all the carbon atoms of the molecule experience a simultaneous radial vibration. After adding hydrogen to the $\mathrm{C}_{60}$ structure, this mode shape will change slightly (Figure 4). The amount of the frequency corresponding to this mode shape and the radius of gyration of the fullerene hydrides, both calculated from the AIREBO potential and DFT, are presented in Table 2. The values given in the brackets are the results of the DFT method. As it can be seen in this table, the results obtained from AIREBO potential 

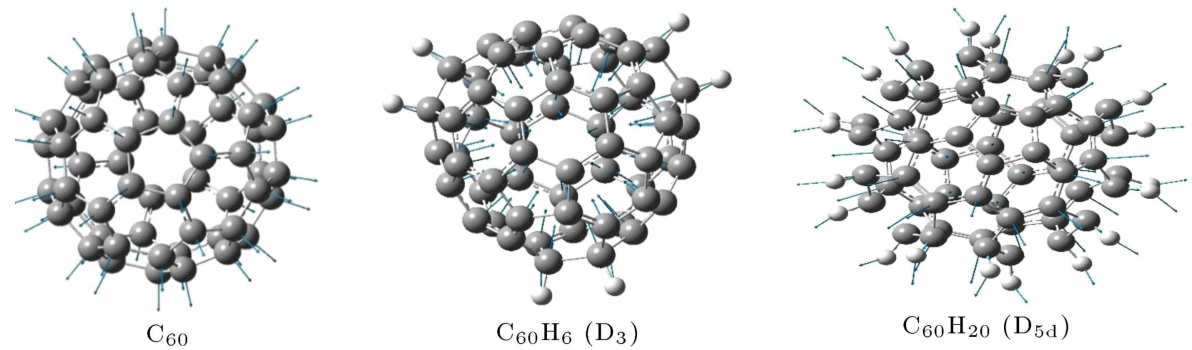

Figure 4. The eigenvectors related to the breathing $\left(A_{g}(1)\right)$ mode.

Table 2. Breathing mode frequency and radius of gyration of fullerene hydrides.

\begin{tabular}{|c|c|c|c|c|c|c|c|}
\hline Molecule & Symmetry & $\begin{array}{l}\text { Breathing } \\
\text { mode } \\
\text { frequency } \\
\left(\mathrm{cm}^{-1}\right)\end{array}$ & $\begin{array}{c}\text { Radius of } \\
\text { gyration } \\
(\AA)\end{array}$ & Molecule & Symmetry & $\begin{array}{l}\text { Breathing } \\
\text { mode } \\
\text { frequency } \\
\left(\mathrm{cm}^{-1}\right)\end{array}$ & $\begin{array}{c}\text { Radius of } \\
\text { gyration } \\
(\AA)\end{array}$ \\
\hline $\mathrm{C}_{60}$ & & $482.7[495.9]$ & $3.55[3.56]$ & $\mathrm{C}_{60} \mathrm{H}_{20}$ & $D_{5 d}$ & $402.9[405.3]$ & $3.64[3.68]$ \\
\hline $\mathrm{C}_{60} \mathrm{H}_{2}$ & $C_{2 v}$ & $478.5[488.7]$ & $3.55[3.57]$ & $\mathrm{C}_{60} \mathrm{H}_{20}$ & $C_{s}$ & $476.5[472.6]$ & $3.62[3.67]$ \\
\hline $\mathrm{C}_{60} \mathrm{H}_{2}$ & $C_{s}$ & $479.5[486.3]$ & $3.55[3.57]$ & $\mathrm{C}_{60} \mathrm{H}_{22}$ & $C_{s}$ & $471.2[464.9]$ & $3.63[3.68]$ \\
\hline $\mathrm{C}_{60} \mathrm{H}_{2}$ & $C_{1}$ & $471.0[486.1]$ & $3.55[3.56]$ & $\mathrm{C}_{60} \mathrm{H}_{24}$ & $C_{2}$ & 388.4 [395.5] & $3.69[3.70]$ \\
\hline $\mathrm{C}_{60} \mathrm{H}_{4}$ & $C_{s}$ (No. 1$)$ & $478.0[485.2]$ & $3.56[3.59]$ & $\mathrm{C}_{60} \mathrm{H}_{24}$ & $C_{1}$ & $471.4[446.6]$ & $3.63[3.69]$ \\
\hline $\mathrm{C}_{60} \mathrm{H}_{4}$ & $C_{s}($ No. 2$)$ & $475.2[481.7]$ & $3.56[3.59]$ & $\mathrm{C}_{60} \mathrm{H}_{26}$ & $C_{s}$ & $460.3[448.1]$ & $3.64[3.71]$ \\
\hline $\mathrm{C}_{60} \mathrm{H}_{4}$ & $C_{s}($ No. 3$)$ & $476.6[479.9]$ & $3.56[3.59]$ & $\mathrm{C}_{60} \mathrm{H}_{28}$ & $C_{1}$ & $487.9[440.6]$ & $3.65[3.72]$ \\
\hline $\mathrm{C}_{60} \mathrm{H}_{4}$ & $D_{2 h}$ & $475.5[484.3]$ & $3.56[3.59]$ & $\mathrm{C}_{60} \mathrm{H}_{30}$ & $C_{1}$ & $422.3[472.3]$ & $3.66[3.73]$ \\
\hline $\mathrm{C}_{60} \mathrm{H}_{6}$ & $D_{3}$ & $471.1[478.8]$ & $3.57[3.60]$ & $\mathrm{C}_{60} \mathrm{H}_{32}$ & $C_{1}$ & $496.2[469.1]$ & $3.67[3.74]$ \\
\hline $\mathrm{C}_{60} \mathrm{H}_{6}$ & $C_{3}$ & $473.3[474.8]$ & $3.57[3.60]$ & $\mathrm{C}_{60} \mathrm{H}_{34}$ & $\mathrm{C}_{s}$ & $386.9[375.7]$ & $3.68[3.74]$ \\
\hline $\mathrm{C}_{60} \mathrm{H}_{8}$ & $\mathrm{C}_{s}$ & $480.2[482.4]$ & $3.58[3.61]$ & $\mathrm{C}_{60} \mathrm{H}_{36}$ & $T$ & $455.8[457.5]$ & $3.66[3.74]$ \\
\hline $\mathrm{C}_{60} \mathrm{H}_{10}$ & $C_{s}$ & $474.2[482.5]$ & 3.59 [3.62] & $\mathrm{C}_{60} \mathrm{H}_{36}$ & $C_{3}($ No. 64$)$ & 426.4 [395.9] & $3.70[3.76]$ \\
\hline $\mathrm{C}_{60} \mathrm{H}_{12}$ & $C_{1}$ & $471.5[476.4]$ & $3.60[3.63]$ & $\mathrm{C}_{60} \mathrm{H}_{36}$ & $C_{1}$ & $421.8[390.9]$ & $3.70[3.76]$ \\
\hline $\mathrm{C}_{60} \mathrm{H}_{14}$ & $C_{s}$ & $468.1[425.0]$ & $3.61[3.64]$ & $\mathrm{C}_{60} \mathrm{H}_{36}$ & $C_{3}$ (No. 3 ) & $455.8[472.7]$ & $3.68[3.76]$ \\
\hline $\mathrm{C}_{60} \mathrm{H}_{16}$ & $C_{s}$ & $493.1[417.1]$ & $3.62[3.66]$ & $\mathrm{C}_{60} \mathrm{H}_{36}$ & $C_{3}$ (No. 4$)$ & $429.2[414.8]$ & $3.68[3.76]$ \\
\hline $\mathrm{C}_{60} \mathrm{H}_{18}$ & $C_{3 v}(1-2$ add $)$ & $487.6[477.5]$ & $3.61[3.66]$ & $\mathrm{C}_{60} \mathrm{H}_{36}$ & $\mathrm{~T}_{h}$ & $418.7[398.4]$ & $3.73[3.76]$ \\
\hline $\mathrm{C}_{60} \mathrm{H}_{18}$ & $C_{3 v}(1-4$ add $)$ & $438.1[437.2]$ & $3.63[3.66]$ & $\mathrm{C}_{60} \mathrm{H}_{36}$ & $D_{3 d}$ & $355.4[422.4]$ & $3.72[3.76]$ \\
\hline $\mathrm{C}_{60} \mathrm{H}_{18}$ & $C_{3}$ & $445.4[458.3]$ & 3.63 [3.67] & $\mathrm{C}_{60} \mathrm{H}_{36}$ & $D_{3 d^{\prime}}$ & $321.6[371.8]$ & $3.69[3.75]$ \\
\hline $\mathrm{C}_{60} \mathrm{H}_{18}$ & $C_{2}$ & $397.1[412.5]$ & $3.64[3.67]$ & $\mathrm{C}_{60} \mathrm{H}_{36}$ & $S_{6}($ No. 88$)$ & $411.7[357.4]$ & $3.68[3.75]$ \\
\hline $\mathrm{C}_{60} \mathrm{H}_{18}$ & $C_{3 v}$ & $490.1[477.3]$ & $3.61[3.66]$ & $\mathrm{C}_{60} \mathrm{H}_{36}$ & $S_{6}($ No. 91$)$ & $398.7[344.6]$ & $3.71[3.75]$ \\
\hline
\end{tabular}

and DFT are close to each other in predicting the breathing mode frequency and the radius of gyration.

The method proposed in this paper is capable of calculating natural frequencies and mode shapes of a molecule, such as $\mathrm{C}_{60} \mathrm{H}_{2 n}$, at several times higher speed than DFT method, while the accuracy of the results of the proposed method is also acceptable.

In order to hold a better view of the changes in the results obtained from the vibrational analysis of fullerene hydrides, the results of two methods in terms of the number of hydrogen atoms are plotted in Figure 5 (for structures with a number of isomers of 2 or more, the first isomer mentioned in Table 2 is considered). According to this figure, the breathing mode frequency does not have monotonic variations, while the gyration radius of the molecule increases with the increase in the number of hydrogen atoms. Given that in all structures, the breathing mode frequency is less than that obtained for the fullerene molecule, it can generally be deduced that by adding hydrogen to $\mathrm{C}_{60}$, the breathing mode frequency decreases.

Figure 6 shows the variations in the breathing mode frequency and radius of gyration for different isomers of the $\mathrm{C}_{60} \mathrm{H}_{36}$ structure. The numbering order in this figure is based on the order in Table 2. As seem in this figure, the breathing mode frequencies of different 


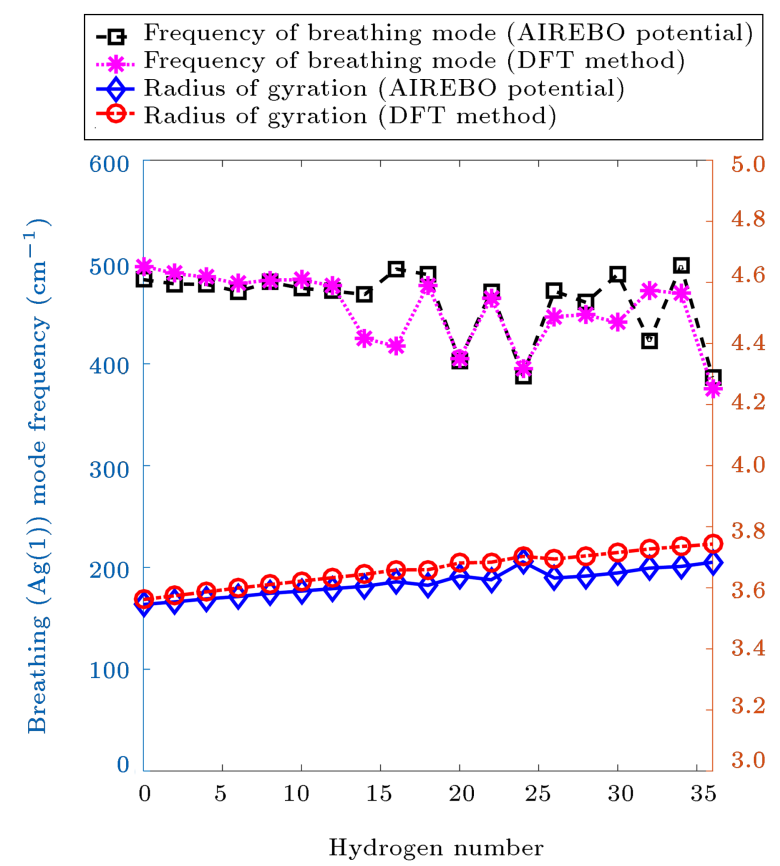

Figure 5. Variation of breathing mode $\left(A_{g}(1)\right)$ frequency and radius of gyration in some fullerene hydrides when the number of hydrogen atoms changes in the structure.

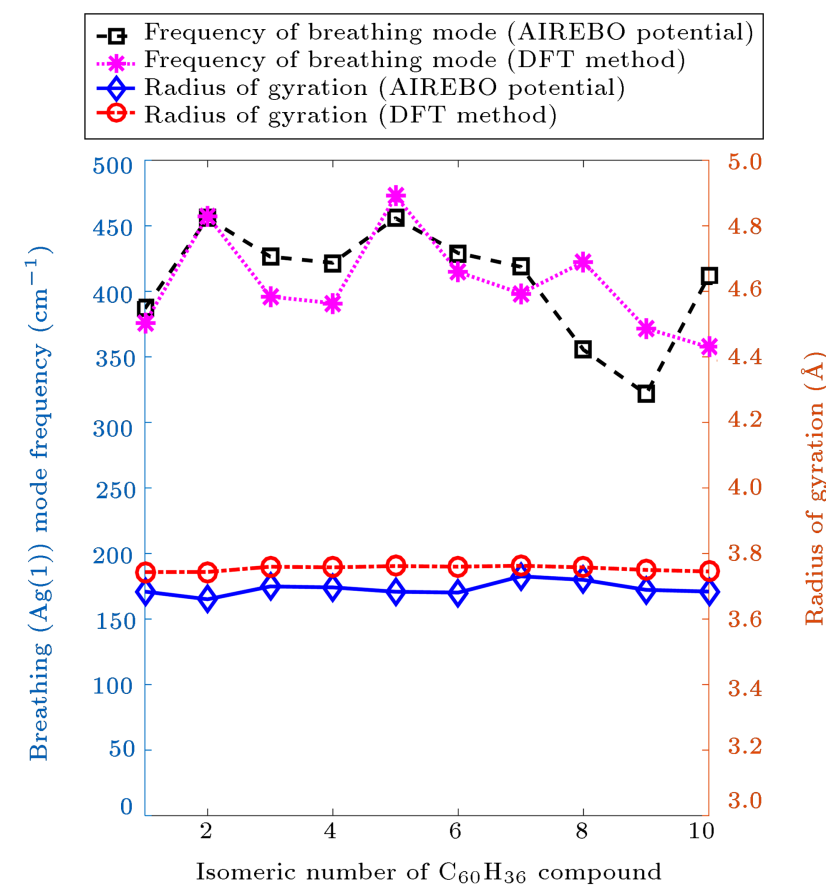

Figure 6. Breathing $\left(A_{g}(1)\right)$ mode frequency and radius of gyration for several isomers of $\mathrm{C}_{60} \mathrm{H}_{36}$ molecule.

isomers of $\mathrm{C}_{60} \mathrm{H}_{36}$ are not equal and about $100 \mathrm{~cm}^{-1}$ difference is observed between their maximum and minimum values, while the gyration radii of isomers are almost the same. Regarding this diagram, it can be pointed out that although the number of hydrogen atoms in fullerene affects the breathing mode frequency

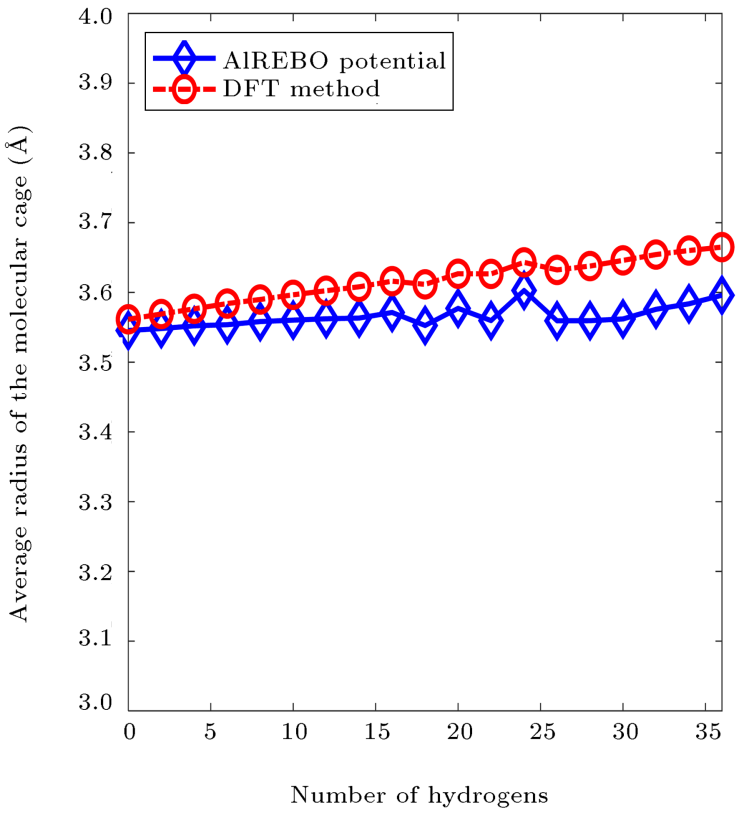

Figure 7. Variation of the mean radius of molecular cage in some fullerene hydrides when the number of hydrogen atoms changes in the structure.

of fullerene hydrides, the position of hydrogen atoms on the $\mathrm{C}_{60}$ cage is also of great importance in determining the amount of this particular frequency. In addition, according to the results obtained from Figure 5 and Figure 6 , the relationship between the gyration radius and the breathing mode frequency of the fullerene hydrides cannot be verified.

Figure 7 demonstrates the changes in the mean radius of the molecular cage of $\mathrm{C}_{60} \mathrm{H}_{2 n}$ structures in terms of the number of hydrogen atoms. It is seen in the figure that the mean radius of the hydro fullerene molecule increases with the increase in the number of hydrogen atoms of the structure, and it seems that this factor is the most important one in the ascending behavior of the radius of gyration in terms of the number of hydrogen atoms.

One of the other most important frequencies of fullerene hydrides is the frequency related to the $\mathrm{C}-$ $\mathrm{H}$ bond vibrations. The number of these frequencies is equal to the number of hydrogen atoms in the structure and in their related mode shape, only the atoms attached to the $\mathrm{C}-\mathrm{H}$ bonds vibrate along those bonds. In Table 3, there is a comparison between the results of the DFT method and the potential-based method in calculating the minimum and maximum frequencies of the $\mathrm{C}-\mathrm{H}$ bond vibrations for some of the fullerene hydrides. The good consistency of the results of the two methods can be deduced from the data in Table 3.

Although other shape modes of fullerene hydrides could also be studied by a comparison between the results of both potential-based and DFT methods for 
Table 3. Minimum and maximum natural frequencies of $\mathrm{C}-\mathrm{H}$ bonds of some hydro fullerenes.

\begin{tabular}{|c|c|c|c|c|c|}
\hline Molecule & Symmetry & $\begin{array}{c}\text { Minimum } \\
\text { natural } \\
\text { frequency } \\
\text { related to C-H } \\
\text { bond-AIREBO } \\
\text { potential }\left(\mathrm{cm}^{-1}\right)\end{array}$ & $\begin{array}{c}\text { Minimum } \\
\text { natural } \\
\text { frequency } \\
\text { related to } \mathrm{C}-\mathrm{H} \\
\text { bond-DFT } \\
\text { method }\left(\mathrm{cm}^{-1}\right)\end{array}$ & $\begin{array}{c}\text { Maximum } \\
\text { natural } \\
\text { frequency } \\
\text { related to C-H } \\
\text { bond-AIREBO } \\
\text { potential }\left(\mathrm{cm}^{-1}\right)\end{array}$ & $\begin{array}{c}\text { Maximum } \\
\text { natural } \\
\text { frequency } \\
\text { related to C-H } \\
\text { bond-DFT } \\
\text { method }\left(\mathrm{cm}^{-1}\right)\end{array}$ \\
\hline $\mathrm{C}_{60} \mathrm{H}_{2}$ & $C_{2 v}$ & 2928.2 & 3031.17 & 2931.0 & 3052.62 \\
\hline $\mathrm{C}_{60} \mathrm{H}_{4}$ & $C_{s}($ No. 1$)$ & 2890.1 & 3022.31 & 2928.4 & 3068.25 \\
\hline $\mathrm{C}_{60} \mathrm{H}_{6}$ & $D_{3}$ & 2928.7 & 3030.94 & 2931.5 & 3053.12 \\
\hline $\mathrm{C}_{60} \mathrm{H}_{12}$ & $C_{1}$ & 2866.5 & 3000.39 & 2933.2 & 3084.28 \\
\hline $\mathrm{C}_{60} \mathrm{H}_{18}$ & $C_{3 v}(1-4$ add $)$ & 2928.9 & 2988.24 & 2968.6 & 3020.55 \\
\hline $\mathrm{C}_{60} \mathrm{H}_{24}$ & $C_{2}$ & 2891.9 & 2969.24 & 2950.9 & 3058.80 \\
\hline $\mathrm{C}_{60} \mathrm{H}_{34}$ & $C_{s}$ & 2853.2 & 2931.09 & 2952.1 & 3076.63 \\
\hline $\mathrm{C}_{60} \mathrm{H}_{36}$ & $T$ & 2884.4 & 2973.31 & 2929.5 & 3075.30 \\
\hline $\mathrm{C}_{60} \mathrm{H}_{36}$ & $T_{h}$ & 2843.6 & 2942.59 & 2929.5 & 3080.24 \\
\hline $\mathrm{C}_{60} \mathrm{H}_{36}$ & $S_{6}($ No. 88$)$ & 2882.0 & 2939.49 & 2925.8 & 3073.84 \\
\hline
\end{tabular}

their frequencies, the complexity of their shapes caused them not to be perused. In fact, when hydrogen is added to the fullerene structure, the shape of the resulting molecule is no longer symmetrical and it is difficult to detect the frequency corresponding to a particular mode shape. For this reason, among all vibrational modes of a $\mathrm{C}_{60} \mathrm{H}_{2 n}$ molecule, only two breathing and $\mathrm{C}-\mathrm{H}$ bond vibrations, which were easily identifiable, were mentioned in this article.

One of the most important uses of hydrogenated fullerenes is in storing hydrogen for exploitation of its energy in the burning process. Although burning hydrogen is high in energy and it does not produce harmful gases such as $\mathrm{CO}_{2}$, which causes heating and pollution of the earth, because of its high reactivity, hydrogen cannot be stored as pure hydrogen gas and needs to be in the structure of some other molecules. Fullerene is one of the most important hydrogen storages and hydrogen can be attached to its cage, directly or by mediation (with the help of alkali metals). It should be noted that for hydrogen to be burnt, separation of hydrogen from the structure of fullerene and its conversion to hydrogen gas is required. After the separation, hydrogen gas can react with oxygen and its energy can be used.

If hydrogen is attached to the fullerene surface without mediation, one of the methods to separate it is to stimulate the shape modes of the $\mathrm{C}-\mathrm{H}$ bond vibrations by radiating high-intensity rays on the structure of the molecule. By stimulating this mode shapes, the vibrations of the molecule are only limited to the oscillations of atoms connected to the $\mathrm{C}-\mathrm{H}$ bonds. Hence, it is possible to increase the amplitude of the oscillations of the atoms by increasing the intensity of the radiated wave and cause the hydrogen atom to separate from the fullerene structure. In various mode shapes related to the $\mathrm{C}-\mathrm{H}$ bond vibrations of $\mathrm{C}_{60} \mathrm{H}_{2 n}$ molecules, the number of mobile atoms varies.

It is advised that the wavelength of the radiated ray should be equal to the frequency of the mode shape with the maximum number of vibrating atoms in order to separate more hydrogen atoms from the structure of the molecule. Figure 8 shows three mode shapes related to the molecule $\mathrm{C}_{60} \mathrm{H}_{36}(\mathrm{~T})$. In each of them,

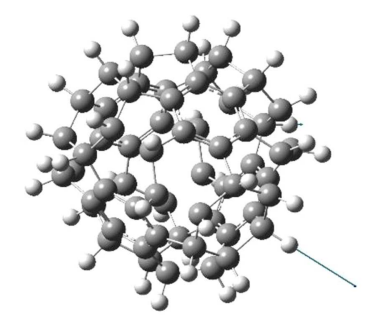

$2978.76 \mathrm{~cm}^{-1}$

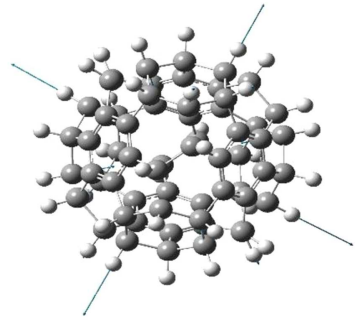

$3064.58 \mathrm{~cm}^{-1}$

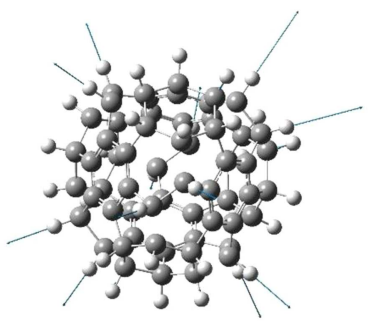

$3016.51 \mathrm{~cm}^{-1}$

Figure 8. Three $\mathrm{C}-\mathrm{H}$ bond shape modes of $\mathrm{C}_{60} \mathrm{H}_{36}(\mathrm{~T})$. 
Table 4. Frequencies corresponds to the $\mathrm{C}-\mathrm{H}$ bond vibrations of fullerene hydride molecules with the maximum number of mobile hydrogen atoms.

\begin{tabular}{ccc}
\hline Molecule & $\begin{array}{c}\text { Frequency } \\
\text { value } \\
\text { (cm }\end{array}$ & $\begin{array}{c}\text { Number of } \\
\text { mobile }\end{array}$ \\
$\begin{array}{c}\text { hydrogen } \\
\text { atoms }\end{array}$ \\
\hline $\mathrm{C}_{60} \mathrm{H}_{18}\left(C_{3 v}(1-2\right.$ add $\left.)\right)$ & 3001.57 & 7 \\
$\mathrm{C}_{60} \mathrm{H}_{18}\left(C_{3 v}(1-4\right.$ add $\left.)\right)$ & 2992.13 & 7 \\
$\mathrm{C}_{60} \mathrm{H}_{18}\left(C_{3}\right)$ & 3029.64 & 6 \\
$\mathrm{C}_{60} \mathrm{H}_{36}(T)$ & 3016.51 & 12 \\
$\mathrm{C}_{60} \mathrm{H}_{36}\left(C_{3}(\right.$ No. 64$\left.)\right)$ & 3075.07 & 8 \\
$\mathrm{C}_{60} \mathrm{H}_{36}\left(C_{1}\right)$ & 3075.80 & 10 \\
$\mathrm{C}_{60} \mathrm{H}_{36}\left(C_{3}\right.$ (No. 3)) & 3040.52 & 7 \\
$\mathrm{C}_{60} \mathrm{H}_{36}\left(C_{3}\right.$ (No. 4)) & 3023.64 & 12 \\
$\mathrm{C}_{60} \mathrm{H}_{36}\left(T_{h}\right)$ & 2951.07 & 20 \\
$\mathrm{C}_{60} \mathrm{H}_{36}\left(D_{3 d}\right)$ & 2961.46 & 16 \\
$\mathrm{C}_{60} \mathrm{H}_{36}\left(D_{3 d^{\prime}}\right)$ & 3027.54 & 13 \\
$\mathrm{C}_{60} \mathrm{H}_{36}\left(S_{6}\right.$ (No. 88)) & 3039.57 & 9 \\
$\mathrm{C}_{60} \mathrm{H}_{36}\left(S_{6}\right.$ (No. 91)) & 3084.91 & 12 \\
\hline
\end{tabular}

the number of mobile atoms is different. One hydrogen atom moves at the frequency of $2978.76 \mathrm{~cm}^{-1}$, four hydrogen atoms at the frequency of $3064.58 \mathrm{~cm}^{-1}$, and 12 hydrogen atoms at the frequency of $3016.51 \mathrm{~cm}^{-1}$. Since the adjustment of the wavelength of the radiated ray on the surface of the fullerene hydride to separate the maximum number of hydrogen atoms from the structure depends strongly on the proper recognition of the frequencies and the mode shapes of the molecules, it is necessary to identify all vibrational features of the molecules in an appropriate manner. It is recommended to use a very efficient method in terms of accuracy and computational time, such as the method presented in this paper. In Table $4, \mathrm{C}_{60} \mathrm{H}_{18}$ and $\mathrm{C}_{60} \mathrm{H}_{36}$ isomers along with a frequency of the $\mathrm{C}-\mathrm{H}$ bond vibrations corresponding to the maximum number of mobile hydrogen atoms are presented. The results of this table were obtained by the DFT method.

\section{Conclusion}

In this paper, a potential-based method was used to predict the vibrational properties of fullerene hydrides. Furthermore, radius of gyration for each $\mathrm{C}_{60} \mathrm{H}_{2 n}$ molecule was calculated through minimization. The interatomic potential used in these calculations was Adaptive Intermolecular Reactive Empirical Bond Order (AIREBO). To evaluate the accuracy of vibrational analysis, the results of AIREBO potential were compared with the results of quantum mechanics and previous experiments. The comparison demonstrated that the AIREBO potential in the innovate potential- based method was able to calculate the natural frequencies of the fullerene hydrides with a fairly good accuracy and low computational effort. The other important achievements of this study are as follows:

- Generally, the breathing mode frequency of the fullerene hydrides is less than that of the fullerene molecule;

- The radius of gyration of $\mathrm{C}_{60} \mathrm{H}_{2 n}$ molecules increases as the number of hydrogen atoms increases;

- There is no clear relationship between the radius of gyration and the breathing mode frequency of the hydro fullerene;

- The radius of gyration for all $\mathrm{C}_{60} \mathrm{H}_{2 n}$ molecules considered in this paper was underestimated by AIREBO potential;

- Although the amount of frequency associated with a particular mode shape for fullerene hydrides depends on the number of hydrogens in the structure, it has a strong dependence on the position of the hydrogen atoms on the $\mathrm{C}_{60}$ molecule;

- The computational cost of Density Functional Theory (DFT) is several times more than that of the proposed potential-based method.

\section{References}

1. Kroto, H.W., Heath, J.R., O'Brien, S.C., et al. " $\mathrm{C}_{60}$ : buckminsterfullerene", Nature, 318(6042), pp. 162163 (1985).

2. Thotakura, N., Sharma, G., Singh, B., Kumar, V., and Raza, K. "Aspartic acid derivatized hydroxylated fullerenes as drug delivery vehicles for docetaxel: An explorative study", Artificial Cells, Nanomedicine, and Biotechnology, 46(8), pp. 1763-1772 (2018).

3. Moha jeri, M., Behnam, B., and Sahebkar, A. "Biomedical applications of carbon nanomaterials: Drug and gene delivery potentials", Journal of Cellular Physiology, 234(1), pp. 298-319 (2018).

4. Olov, N., Bagheri-Khoulenjani, S., and Mirzadeh, H. "Combinational drug delivery using nanocarriers for breast cancer treatments: A review", Journal of Biomedical Materials Research Part A, 106(8), pp. 2272-2283 (2018).

5. Fakhraee, S. and Souri, M. "Deformation density components analysis of fullerene-based anti-HIV drugs", Journal of Molecular Modeling, 20(11), p. 2486 (2014).

6. Faraji, H., Nedaeinia, R., Nourmohammadi, E., Malaekeh-Nikouei, B., Sadeghnia, H.R., Ziapour, S.P., Sarkarizi, H.K, and Oskuee R.K. "A review on application of novel solid nanostructures in drug delivery", In Journal of Nano Research, 53(1), pp. 22-36 (2018).

7. Hu, Y., Shenderova, O.A., Hu, Z., et al. "Carbon nanostructures for advanced composites", Reports on Progress in Physics, 69(6), p. 1847 (2006). 
8. Barrera, E.V., Sims, J., Callahan, D.L., et al. "Processing of fullerene-reinforced composites", Journal of Materials Research, 9(10), pp. 2662-2669 (1994).

9. Dang, B., Hu, J., Zhou, Y., et al. "Remarkably improved electrical insulating performances of lightweight polypropylene nanocomposites with fullerene", Journal of Physics D: Applied Physics, 50(45), p. 455303 (2017).

10. Miura, K., Kamiya, S., and Sasaki, N. " $\mathrm{C}_{60}$ molecular bearings", Physical Review Letters, 90(5), p. 055509 (2003).

11. Legoas, S.B., Giro, R., and Galvao, D.S. "Molecular dynamics simulations of $\mathrm{C}_{60}$ nanobearings", Chemical Physics Letters, 386(4), pp. 425-429 (2004).

12. Pishkenari, H.N., Nemati, A., Meghdari, A., et al. "A close look at the motion of $\mathrm{C}_{60}$ on gold", Current Applied Physics, 15(11), pp. 1402-1411 (2015).

13. Nemati, A., Pishkenari, H.N., Meghdari, A., et al. "Directing the diffusive motion of fullerene-based nanocars using nonplanar gold surfaces", Physical Chemistry Chemical Physics, 20(1), pp. 332-344 (2018).

14. Shirai, Y., Osgood, A.J., Zhao, Y., et al. "Directional control in thermally driven single-molecule nanocars", Nano Lett, 5(11), pp. 2330-2334 (2005).

15. Ahangari, M.G., Ganji, M.D., and Jalali, A. "Interaction between fullerene-wheeled nanocar and gold substrate: A DFT study", Physica E: Low-Dimensional Systems and Nanostructures, 83, pp. 174-179 (2016).

16. Nemati, A., Meghdari, A., Pishkenari, H.N., et al. "Investigation into thermally activated migration of fullerene-based nanocars", Scientia Iranica, 25(3), pp. 1835-1848 (2018).

17. Nemati, A., Pishkenari, H.N., Meghdari, A., et al. "Nanocar \& nanotruck motion on gold surface", IEEE International Conference on Manipulation, Automation, and Robotics at Small Scales (MARSS), pp. 1-6 (2016).

18. Varma, C.M., Zaanen, J., and Raghavachari, K. "Superconductivity in the fullerenes", Science, 254(5034), pp. 989-992 (1991).

19. Joachim, C., Gimzewski, J.K., and Aviram, A. "Electronics using hybrid-molecular and mono-molecular devices", Nature, 408(6812), pp. 541-548 (2000).

20. Doh, J. and Lee, J. "Prediction of the mechanical behavior of double walled-CNTs using a molecular mechanics-based finite element method: Effects of chirality", Computers \& Structures, 169, pp. 91-100 (2016).

21. Avila, A.F., Eduardo, A.C., and Neto, A.S. "Vibrational analysis of graphene based nanostructures", Computers \& Structures, 89(11-12), pp. 878-892 (2011).

22. Meilunas, R., Chang, R.P.H., Liu, S., et al. "Infrared and Raman spectra of $\mathrm{C}_{60}$ and $\mathrm{C}_{70}$ solid films at room temperature", Journal of Applied Physics, 70(9), pp. 5128-5130 (1991).
23. Neugebauer, J., Reiher, M., Kind, C., et al. "Quantum chemical calculation of vibrational spectra of large molecules-Raman and IR spectra for buckminsterfullerene", Journal of Computational Chemistry, 23(9) pp. 895-910 (2002).

24. Adams, G.B., Page, J.B., Sankey, O.F., et al. "Firstprinciples quantum molecular-dynamics study of the vibrations of icosahedral $\mathrm{C}_{60}$ ", Physical Review B., 44(8) p. 4052 (1991).

25. Negri, F., Orlandi, G., and Zerbetto, F. "Quantumchemical investigation of Franck-Condon and JahnTeller activity in the electronic spectra of Buckminsterfullerene", Chemical Physics Letters, 144(1), pp. 31-37 (1988).

26. Giannozzi, P. and Baroni, S. "Vibrational and dielectric properties of $\mathrm{C}_{60}$ from density-functional perturbation theory", The Journal of Chemical Physics, 100(11), pp. 8537-8539 (1994).

27. Ansari, R., Sadeghi, F., and Ajori, S. "Continuum and molecular dynamics study of $\mathrm{C}_{60}$ fullerene-carbon nanotube oscillators", Mechanics Research Communications, 47, pp. 18-23 (2013).

28. Ghavanloo, E. and Fazelzadeh, S.A. "Continuum modeling of breathing-like modes of spherical carbon onions", Physics Letters A., 379(26), pp. 1600-1606 (2015).

29. Adhikari, S. and Chowdhury, R. "Vibration spectra of fullerene family", Physics Letters A. 375(22), pp. 2166-2170 (2011).

30. Pishkenari, H.N. and Ghanbari, P.G. "Vibrational analysis of the fullerene family using Tersoff potential", Current Applied Physics, 17(1), pp. 72-77 (2017).

31. Pishkenari, H.N. and Ghanbari, P.G. "Vibrational properties of $\mathrm{C}_{60}$ : A comparison among different interatomic potentials", Computational Materials Science, 122, pp. 38-45 (2016).

32. Jing, D. and Pan, Z. "Molecular vibrational modes of $\mathrm{C}_{60}$ and $\mathrm{C}_{70}$ via finite element method", European Journal of Mechanics-A/Solids, 28(5), pp. 948-954 (2009).

33. Braun, M., Aranda-Ruiz, J., Rodr 1guez-Millán, M., et al. "On the bulk modulus and natural frequency of fullerene and nanotube carbon structures obtained with a beam based method", Composite Structures, 187, pp. 10-17 (2018).

34. Sarvi, M.N. and Ahmadian, M.T. "Static and vibrational analysis of fullerene using a newly designed spherical super element", Scientia Iranica, 19(5), pp. 1316-1323 (2012).

35. Lee, J.H., Lee, B.S., Au, F.T.K., et al. "Vibrational and dynamic analysis of $\mathrm{C}_{60}$ and $\mathrm{C}_{30}$ fullerenes using FEM", Computational Materials Science, 56, pp. 131140 (2012).

36. Eisler, H.-J., Gilb, S., Hennrich, F.H., et al. "Low frequency raman active vibrations in fullerenes. 1. Monopolar modes", The Journal of Physical Chemistry A., 104(8), pp. 1762-1768 (2000). 
37. Dresselhaus, M.S., Jorio, A., Dresselhaus, G., et al. "Raman spectroscopy of nanoscale carbons and of an isolated carbon nanotube", Molecular Crystals and Liquid Crystals, $\mathbf{3 8 7}(1)$, pp. 21-29 (2002).

38. Ghavanloo, E., Fazelzadeh, S.A., and Rafii-Tabar, H. "Analysis of radial breathing-mode of nanostructures with various morphologies: a critical review", International Materials Reviews, 60(6), pp. 312-329 (2015).

39. Ghavanloo, E. and Fazelzadeh, S.A. "Nonlocal shell model for predicting axisymmetric vibration of spherical shell-like nanostructures", Mechanics of Advanced Materials and Structures, 22(7), pp. 597-603 (2015).

40. Khan, A.I., Navid, I.A., Noshin, M., et al. "Equilibrium molecular dynamics (MD) simulation study of thermal conductivity of graphene nanoribbon: A comparative study on MD potentials", Electronics, 4(4), pp. 1109-1124 (2015).

41. Matus, M. and Kuzmany, H. "Raman spectra of singlecrystal C60", Applied Physics A: Materials Science \& Processing, 56(3), pp. 241-248 (1993).

42. Meletov, K.P., Krestinin, A.V., Arvanitidis, J., et al. "Temperature effects in the Raman spectra of bundled single-wall carbon nanotubes", Chemical Physics Letters, 477(4), pp. 336-339 (2009).

43. Kwon, Y.-K., Berber, S., and Tománek, D. "Thermal contraction of carbon fullerenes and nanotubes", Physical Review Letters, 92,(1) p. 015901 (2004).

44. Drelinkiewicz, A., Byszewski, P., and Bielanski, A. "Catalytic hydrogenation of $\mathrm{C}_{60}$ fullerene", Reaction Kinetics and Catalysis Letters, 59(1) pp. 19-27 (1996).

45. Jin, C., Hettich, R., Compton, R., et al. "Direct solidphase hydrogenation of fullerenes", The Journal of Physical Chemistry, 98(16), pp. 4215-4217 (1994).

46. Osaki, T., Tanaka, T., and Tai, Y. "Hydrogenation of $\mathrm{C}_{60}$ on alumina-supported nickel and thermal properties of $\mathrm{C}_{60} \mathrm{H}_{36}$ ", Physical Chemistry Chemical Physics, 1(9), pp. 2361-2366 (1999).

47. Billups, W.E., Luo, W., Gonzalez, A., et al. "Reduction of $\mathrm{C}_{60}$ using anhydrous hydrazine", Tetrahedron Letters, 38(2), pp. 171-174 (1997).

48. Mandrus, D., Kele, M., Hettich, R.L., et al. "Sonochemical synthesis of $\mathrm{C}_{60} \mathrm{H}_{2}$ ", The Journal of Physical Chemistry B., 101(2), pp. 123-128 (1997).

49. Morosin, B., Henderson, C., and Schirber, J.E. "Stoichiometrically controlled direct solid-state synthesis of $\mathrm{C}_{60} \mathrm{H}_{2} "$, Applied Physics A, 59(2), pp. 179-180 (1994).

50. Rüchardt, C., Gerst, M., Ebenhoch, J., et al. "Transfer hydrogenation and deuteration of buckminsterfullerene $\mathrm{C}_{60}$ by 9 , 10-dihydroanthracene and $9,9^{\prime}$, 10, $10^{\prime}[\mathrm{D} 4]$ dihydroanthracene", Angewandte Chemie International Edition, 32(4), pp. 584-586 (1993).

51. Cataldo, F. and Iglesias-Groth, S., Fulleranes: The Hydrogenated Fullerenes, 2, Springer Science \& Business Media (2010).
52. Tokunaga, K., Ohmori, S., Kawabata, H., et al. "A density functional theory study on the hole transfer in fullerene hydride $\mathrm{C}_{60} \mathrm{H}_{2}$ ", Japanese Journal of Applied Physics, 47(2R), p. 1089 (2008).

53. Tokunaga, K., Kawabata, H., and Matsushige, K. "Improvement in hole-transport property of fullerene materials by hydrogenation: A density functional theory study on fullerene hydride $\mathrm{C}_{60} \mathrm{H}_{4}$ ", Japanese Journal of Applied Physics, 47(5R), p. 3638 (2008).

54. Haufler, R.E., Conceicao, J., Chibante, L.P.F., et al. "Efficient production of $\mathrm{C}_{60}$ (buckminsterfullerene), $\mathrm{C}_{60} \mathrm{H}_{36}$, and the solvated buckide ion", Journal of Physical Chemistry, 94(24), pp. 8634-8636 (1990).

55. Nechaev, Y.S. and Ol'ga, K.A. "Methodological, applied and thermodynamic aspects of hydrogen sorption by graphite and related carbon nanostructures", Russian Chemical Reviews, 73(12), pp. 1211-1238 (2004).

56. Karpushenkava, L.S., Kabo, G.J., and Diky, V.V. "Thermodynamic properties and hydrogen accumulation ability of fullerene hydride $\mathrm{C}_{60} \mathrm{H}_{36}$ ", Fullerenes, Nanotubes, and Carbon Nanostructures, 15(4), pp. 227-247 (2007).

57. Beardmore, K., Smith, R., Richter, A., et al. "The interaction of hydrogen with $\mathrm{C}_{60}$ fullerenes", Journal of Physics: Condensed Matter, 6(36), p. 7351 (1994).

58. Bini, R., Ebenhoch, J., Fanti, M., et al. "The vibrational spectroscopy of $\mathrm{C}_{60} \mathrm{H}_{36}$ : An experimental and theoretical study", Chemical Physics, 232(1-2), pp. 75-94 (1998).

59. Popov, A.A., Senyavin, V.V., Granovsky, A.A., et al., "Vibrational spectra and molecular structure of the hydrofullerenes $\mathrm{C}_{60} \mathrm{H}_{18}, \mathrm{C}_{60} \mathrm{D}_{18}$, and $\mathrm{C}_{60} \mathrm{H}_{36}$ as studied by IR and Raman spectroscopy and firstprinciple calculations", in Hydrogen Materials Science and Chemistry of Carbon Nanomaterials, Springer, pp. 347-356 (2004).

60. Bensasson, R.V., Hill, T.J., Land, E.J., et al. "Spectroscopy and photophysics of $\mathrm{C}_{60} \mathrm{H}_{18}$ and $\mathrm{C}_{60} \mathrm{H}_{36}$ ", Chemical Physics, 215(1), pp. 111-123 (1997).

61. Meletov, K.P., Assimopoulos, S., Tsilika, I., et al. "Isotopic and isomeric effects in high-pressure hydrogenated fullerenes studied by Raman spectroscopy", Chemical Physics, 263(2-3), pp. 379-388 (2001).

62. Balasubramanian, K. "Enumeration of isomers of polysubstituted $\mathrm{C}_{60}$ and application to NMR", Chemical Physics Letters, 182(3-4), pp. 257-262 (1991).

63. Clare, B.W. and Kepert, D.L. "Structures, stabilities and isomerism in $\mathrm{C} 60 \mathrm{Hn}, n=2-36$. A comparison of the AM1 Hamiltonian and density functional techniques", Journal of Molecular Structure: THEOCHEM, 622(3), pp. 185-202 (2003).

64. Nossal, J., Saini, R.K., Alemany, L.B., et al. "The synthesis and characterization of fullerene hydrides", European Journal of Organic Chemistry, 2001(22), pp. 4167-4180 (2001). 
65. Brenner, D.W. "Empirical potential for hydrocarbons for use in simulating the chemical vapor deposition of diamond films", Physical Review B., 42(15), p. 9458 (1990).

66. Brenner, D.W., Shenderova, O.A., Harrison, J.A., et al. "A second-generation reactive empirical bond order (REBO) potential energy expression for hydrocarbons", Journal of Physics: Condensed Matter, 14(4), p. 783 (2002).

67. Stuart, S.J., Tutein, A.B., and Harrison, J.A. "A reactive potential for hydrocarbons with intermolecular interactions", The Journal of Chemical Physics, 112(14), pp. 6472-6486 (2000).

68. Stephens, P.J., Devlin, F.J., Chabalowski, C.F.N., et al. "Ab initio calculation of vibrational absorption and circular dichroism spectra using density functional force fields", The Journal of Physical Chemistry, 98(45), pp. 11623-11627 (1994).

69. Hehre, W.J., Ditchfield, R., and Pople, J.A. "Selfconsistent molecular orbital methods. XII. Further extensions of Gaussian-type basis sets for use in molecular orbital studies of organic molecules", The Journal of Chemical Physics, 56(5), pp. 2257-2261 (1972).

70. Chase, B., Herron, N., and Holler, E. "Vibrational spectroscopy of $\mathrm{C}_{60}$ and $\mathrm{C}_{70}$ temperature-dependent studies", Journal of Physical Chemistry, 96(11), pp. 4262-4266 (1992).

\section{Biographies}

Ali Golzari (born on April 11, 1993) received his BSc degree from Khajeh Nasir Toosi University of Technology in 2015. In 2017, he received his MSc degree from Sharif University of Technology and he is currently a $\mathrm{PhD}$ candidate at the same university. He has a great interest in research activities in microelectromechanical systems (MEMS) and molecular dynamics.

Hossein Nejat Pishkenari received his BSc, MSc, and $\mathrm{PhD}$ degrees in Mechanical Engineering from Sharif University of Technology in 2003, 2005, and 2010, respectively. Then, he joined the Department of Mechanical Engineering at the same university in 2012. Currently, he is directing the Computational Nano-mechanics and Nano-robotics Laboratories. His research interests are molecular dynamics, robotics and control, nonlinear dynamics, and vibration. 